\title{
Evaluation of Technological Trends and Demands of the Manufacturing Industry to a Center of R\&D\&I
}

\author{
Leone Peter Correia da Silva Andrade ${ }^{1}$, Markus Will ${ }^{2}$, Luis Alberto Breda Mascarenhas ${ }^{1}$ \\ Rafaela Campos da Silva ${ }^{3 *}$ Jefferson de Oliveira Gomes ${ }^{3}$
}

\begin{abstract}
The manufacturing industry is fairly representative in the Brazilian economy. The research activities in technology, development and innovation promoted by technology centers are of great importance to boost the competitiveness of this segment. In this context, this work aims presenting the development of the strategic planning for a Center of R\&D\&I (Research \& Development \& Innovation), looking 20 years ahead, on a macro level, creating a master plan which summarizes the future focus areas of competence for technology research, development and innovation, coping with manufacturing trends, using a participative workshop approach. Thus, it is expected that this center offer integrated technological solutions with high added value that promote the development and competitiveness of the manufacturing industry, in the prospects for medium and long term. In order to achieve the project objectives taking the principle of strategic planning was followed. On the one hand, focus was placed on the internal perspective analyzing the current status of the Center. On the other hand, the environment of the Center (external perspective) was analyzed. Matching the analysis results regarding both perspectives future competence areas were derived, according to global technological trends as well as national and local industrial demand. Thus, the competencies required to be developed by a technology center to meet the manufacturing industry over the next twenty years would be derived.
\end{abstract}

Keywords: strategic planning; R\&D\&I institute; technological forecasting; megatrends

Submitted August 29th 2015 / Approved October 10th 2015

\section{Introduction}

In recent decades, manufacturing has evolved from a form of more intensive mechanical work for a rich set of processes based on the integration of information and technology (advanced manufacturing). Several countries have prioritized this issue, as is the case of USA, Germany, China, Japan and South Korea. It is under discussion in Brazil the creation of a Knowledge Platform for Advanced Manufacturing, which should develop new products and processes with a high degree innovation, from the coordinated connection of market trends with basic research. Therefore, several long-term research projects should be articulated in topics such as automated control tools, integration of manufacturing modes and virtual systems planning and production control (industry concepts 4.0), contributing to Brazil to achieve new levels of productivity and pass to lead innovation in strategic areas.

The Manufacturing is the foundation of any country's development process. It is in agriculture, mining, on land or on the sea floor, creating products and value-added services. The industry that does not evolve cannot keep up the competitive moves, now effectively globalized. Gain competitive advantage, then, implies not only monitor, but move ahead. And the only known way is the innovation.

Because it is a transversal area running through different production segments, manufacturing contributes to technological development and the consolidation of new processes and products. Deploy a platform like this in Brazil is therefore a cross, interdisciplinary perspective, with great power of capillarity between different fields of knowledge, contributing from basic science to its scale up in the industry.

For Brazil not only stem the decline in the share industry in GDP, but go on to have a manufacture with international relevance is essential to think strategically and set the pillars of this project. The main pillars of this process are described: Virtual Manufacturing - design, virtual prototyping and operation of plants and their processes; Intelligent Manufacturing - aiming to have intelligent production systems enough to self-manage and operate without direct human interference; Additive Manufacturing - streamlining the design process, enabling product design and complex components and application of new technological solutions; Autonomous Systems - Systems incorporation able to perform basic tasks to the operation and integrity of the systems and units autonomously; Systems of Systems - board intelligence in a new perspective for products that can interact with humans and each other; Embedded Services to Products - significantly increase the value of products by incorporating services that will bring more utility to the user, his/her safety and comfort, as well as saving time and resources to society.

The manufacturing industry is representative in the Brazilian economy. The research activities in technology, development and innova-

1 SENAI CIMATEC Bahia, Brazil.

2 Fraunhofer IPK - Institute for Production Systems and Design Technology, Berlim, Germany, 10587

3 ITA - Instituto Tecnológico de Aeronáutica, São Paulo, Brazil.

*Corresponding author: rcampos@ita.br 
tion promoted by R\&D\&I (Research \& Development \& Innovation) institutes are of great importance to boost the competitiveness of this segment. In this context, this work aims presenting the development of the strategic planning for a Center of R\&D\&I, looking 20 years ahead, on a macro level, creating a master plan which summarizes the future focus areas of competence for technology research, development and innovation, coping with manufacturing trends, using a participative workshop approach. Thus, it is expected that this center offer integrated technological solutions with high added value that promote the development and competitiveness of the manufacturing industry, in the prospects for medium and long term.

A method that was used to assess the actual status of the existing activities and areas of competence as well as the existing organizational structure of a Center of R\&D\&I will be presented. New opportunities for future areas of competence were mapped according to global technological trends as well as national and local industrial demand and at the end was presented a plan for the Center, considering 20 years perspective.

\section{Literature Review}

Research institutions must have investment plans in long time horizons to meet the demands of society and have to deal with significant uncertainty, complexity and changes in governance. The achievement of the prospective projects in collaboration with multidisciplinary groups increases organizational resilience, improving the ideation, problem definition, and the consensus in long-horizon strategies. It increases the variety of perspectives in scenario creation, resulting in improved strategic options (Weigand, Flanagan, Dye \& Jones, 2014).

According to Zouain (2001), unlike companies, technological research institutes cannot be judged solely on the basis of market shares or profits. Much of the investment in these institutes corresponds to expenses arising from long-term public goods. The success criteria used must represent a combination of dynamism, relevance to the industry, contribution to the national science and technology infrastructure, financial resource, appreciation from the industry, independent fundraising capacity, innovative organizational approaches, effective management and scientific and technological products valued.

There is not a 'single set of rules' to the institutes, in function, especially from the diversity of their goals and their environments. Each Institute has its own strengths, weaknesses and potential, each one operates in a different economic environment and has its own role to play in its national system of innovation. In practice, the main institutes perform little advanced research. The vision of the technological research institutes as centres of generation technology to the industry is wrong and contributed to the retreating in relation to industry and to the lack of effectiveness of many institutes. It is worth mentioning that the dissemination of new innovations is the task of the industry and not the technological research institutes. Successful activities are highly specialized and carried out in close cooperation with industry and are often the result of long-term collaborations with companies in task-oriented activities and guided by demand (Zouain, 2001).

Suzila, Alinda, Suhadak and Zurinah (2013) explored the characteristic of Research Institutes to identify the differences and similarities of them as compared to business organization and institute of higher learning (IHL). This comparison showed that research institutes are unique and should possess the following characteristics: creativity, innovativeness, productivity, and responsiveness since the organization will continuously to evolve within its environment plus dynamical.

The institute needs to be quick in response to the changes in environment and technology development so that it can seize and exploit opportunities. These are in addition to their normal roles, which are planning, administration and conducting research and development. The type of task in research institutes are usually of non-routine tasks. As the characteristic of research institutes is unique as compare to other type of organization, they require unique method of planning. The dynamically evolve environment of new technology and innovation that they have to produce also sometimes make the research and development effort in research institutes do not have consistent planning. The organization needs to be attentive all the time and must have the capability to capture and exploit the emerging opportunities.

Freitas Filho, Paez and Goedert (2002) reported that there is increasing evidence that the planning of public agricultural research and development (R\&D) organizations must be based on systematic procedures to capture uncertainties and complexities associated with the future of their mission area and incorporate them into the decision-making process both at strategic and operational levels. As a first step, key issues that emerge are: "what be the science and technology (S\&T) needs for the agribusiness sector in the future?" and "how should be R\&D organizations prepared to meet them?". On the one hand, the intensity of S\&T advances and, on the other, the growing and diversified R\&D demands of global markets need to have a different pattern of answers compatible with the new challenges imposed on the sustainability of these organizations at the turn of the 21 st century. In order to answer the first question, it became necessary to redefine the vision of the future, broadened by the relatively long horizon of S\&T planning, considering a set of external environment uncontrollable factors that affect, directly or indirectly, technological trajectories of agricultural research. In answering the second question, it became necessary to review internal management tools that translate this vision of the future into actions that are more in tune with the solution of priority problems of societies in changing economies.

In addition to the agribusiness sector, the questions raised by Freitas Filho, Paez and Goedert (2002) are recurring to R\&D organizations that develop research to the most diverse industrial sectors. Thus, this work aims to contribute to the literature presenting a systematic method to answer the same questions for an R\&D organization that develop research for manufacturing sector: "what be the science and technology (S\&T) needs for the manufacturing sector in the future?" and "how should be R\&D organizations prepared to meet them?". 


\section{Method}

Initially it is important to understand the context in which the center of R\&D\&I is inserted, understand which are the competitors, their role in the research environment, clearly identify its market and how it relates to their market. The Figure 1 shows the positioning of a R\&D\&I center within Brazilian innovation system.

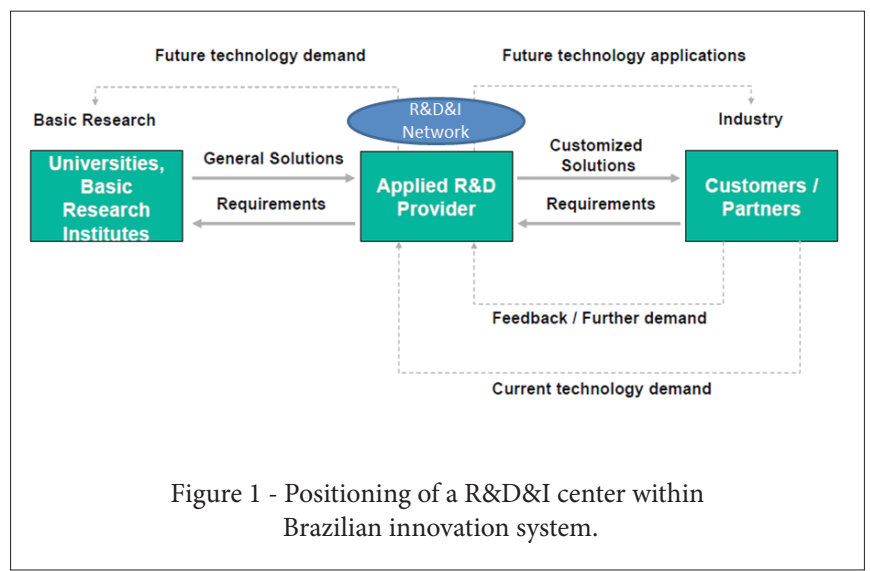

The objective of this study is developing the strategic planning up to 2034 on a macro level, creating a master plan, which summarizes the future focus areas of competence for technology research, development and innovation of a Center of R\&D\&I by using a participative workshop approach. The study comprises the following specific objectives:

- Development of detailed work plan and overall project management;

- Diagnosis of actual status of the existing activities and areas of competence as well as the existing organizational structure;

- Mapping of new opportunities for future areas of competence according to global technological trends as well as national and local industrial demand;

- Master Plan for the Center for the strategic development until 2034.

In order to achieve the project objectives taking the principle of strategic planning is followed (Figure 2). On the one hand, focus is placed on the internal perspective analyzing the current status of the Center. On the other hand, the environment of the Center (external perspective) will be analyzed. Matching the analysis results regarding both perspectives future competence areas will be derived.

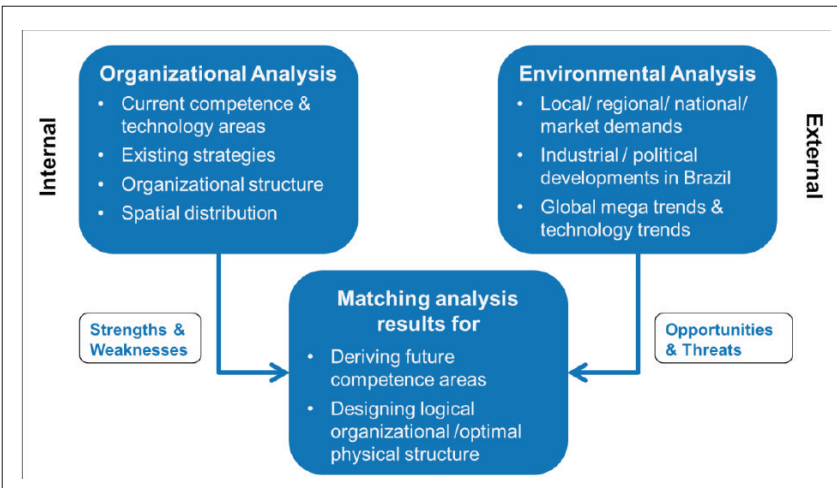

Figure 2. Project Approach Regarding Content.

In the course of the project, the following approach regarding the timeline has to be taken (Figure 3). Matching the actual demand at regional level $\left(t_{0}\right)$ with global long-term trends $\left(t_{2}\right)$ the mid-term demand at national level $\left(\mathrm{t}_{1}\right)$ can be elaborated. Building up on the different demands with the respective time horizon a vision for the Center will be created and brought together with the actual competence areas of the Center to elaborate future competence areas, which cover the estimated mid- and long-term demand at national level.

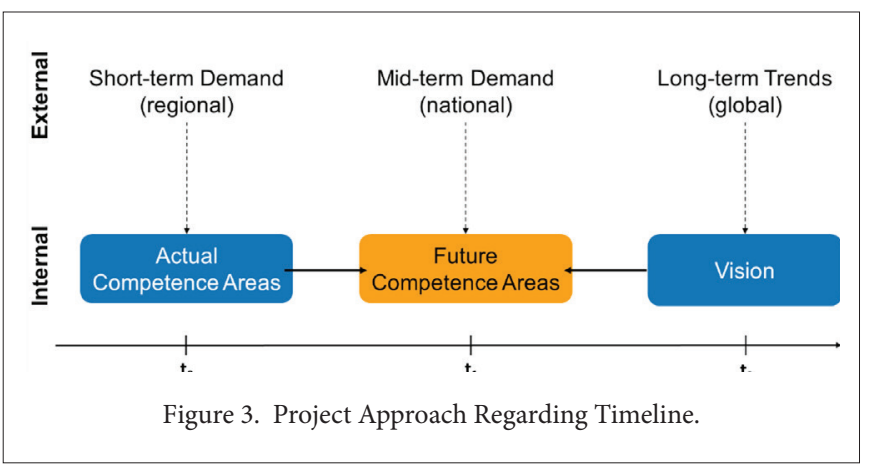

The procedure to detail the strategic planning considers the perspective of the business model, which was named Integrated Strategy Framework (ISF). It will be used as a basis to systematize the analysis of Center's logical value creation (Figure 4). The ISF bundles the different types of services offered by the Center of R\&D\&I under the dimension Service Areas, the different industry sectors focused by the Center under the dimension Industry Sectors and the different fields of competence of the Center under the dimension Competence Areas. In sum, the industry must define what competences the center must have in order to be better able to support this industry. Analyzing in detail the regional and national industry development opportunities should be the main driver to the center decisions. Here should be considered working in networks, so that some competences do not need to be established so deeply, but a comprehensive scope is important. The network performance requires management tools that need to be considered in terms of detail. 


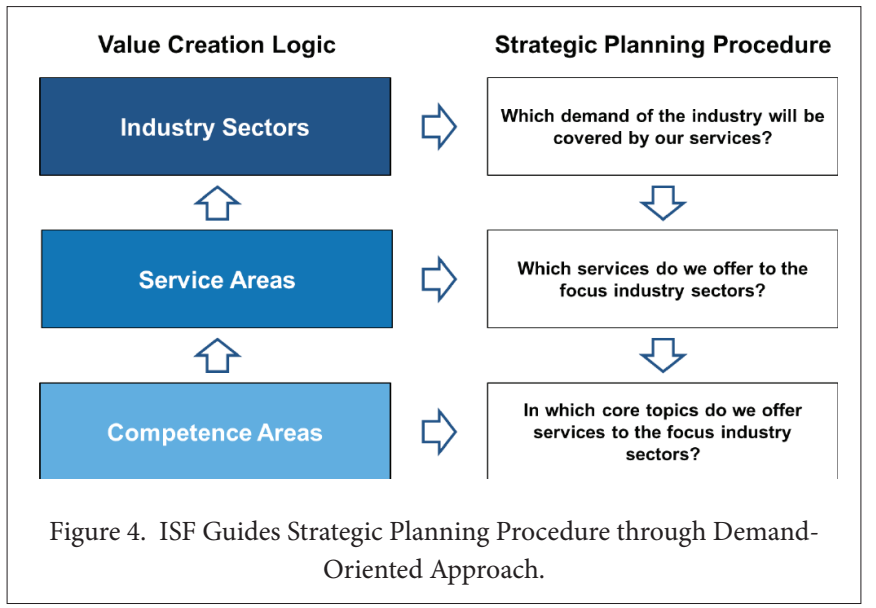

When the service areas, it is related to the strategy of how the portfolio of competences will be delivered. They define the degree of specialization of each product. Products make the bridge from institute to industry and should be used to analyze, refine the degree of supply and demand adherence.

The competences are the focus of this analysis. The definition of where to invest more, which furthermore, when developing and investing in a new area is, perhaps, the most difficult and is the main element of this work.

The elaboration of the study results will be carried out in three steps performed in workshops with a multidisciplinary representative strategy team consisting of key managers of the Center's main organizational units and external experts:

First step -Service Areas of the Center: Shall be described the vision, mission and overall objectives of the Center; the strategic objectives of each main Service Area of the Center; and evaluated the current status of this Service Areas in the quantity, quality and systematic dimensions.

Second step - Focus Industry Sectors of the Center: Must be raised the Global Megatrends that have potential to be picked up by the Brazilian Industry; listed the main trends in the national business environment in political, economic, social and technological dimensions and evaluated their impact on the Service Areas of the Center; identified the global technology trends on long-term perspective; and identified the Industry Sectors that are focused by the Center at national level and their specific mid- to long-term demand; identified the Industry Sectors that are focused by the Center in the short- to mid-term at regional level and evaluated their demand for the Service Areas.

- Third step: Competence Areas of the Center: Shall be elaborated the future Competence Areas for the Center long-term demand-oriented taking into account the competencies already exis- tent at Center in the present and the analysis results regarding Center's focus Industry Sectors.

The following case study will show in detail the application of the proposed method.

\section{Case study}

\subsection{The study case object}

The institute in question, SENAI Bahia/CIMATEC, is located at state of Bahia, northeastern Brazil. The center is structured in matrix form, and includes in its business model three main structures service areas, industry sectors and competence areas. Service areas mean the macro processes of the center and are divided into technical school, technology center and college. College is subdivided in the areas of graduation and post-graduation. Post-graduation along with the technological center are responsible for research and innovation projects. Industrial sectors define the focus of the R\&D\&I Center, it is the translation of market demands. For some competences, the market goes beyond the state's borders and can meet nationally and in some cases internationally. The other sphere is competence areas, which in a more current perspective can only call competences. In them, there are the skills that the center has to carry out their activities with industry, especially the manufacturing industry.

The R\&D\&I Center analyzed is part of a national structure that is much known in terms of education and is creating an important network on technology and innovation institutes and it was considered in this study. The technology center in question was designed in the late 1990s and opened in 2002. The center was structured considering an operating approach that sought to integrate competences to meet industry demands for education, technical and technological services and applied research. In addition to technical education, the center has offered since 2005 undergraduate and graduate degrees, including doctorates. Today, the center is a national emphasis on research and innovation by supporting the industry through its 30 areas of competence.

The study approach regarding timeline for SENAI Bahia/CIMATEC is illustrated in Figure 5.

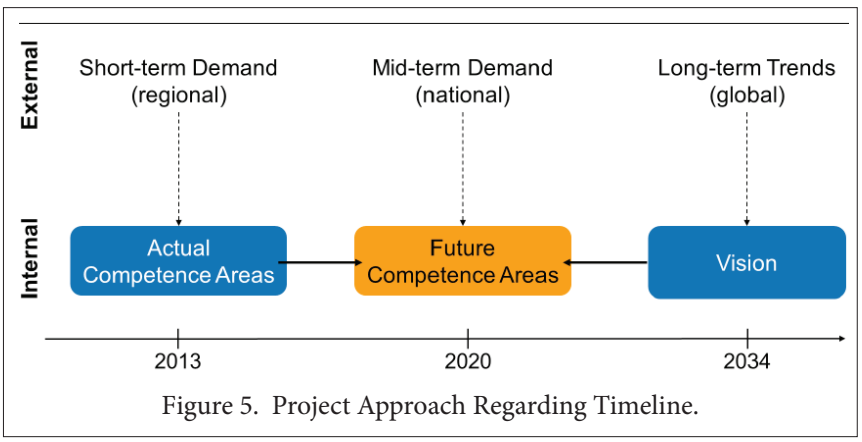




\subsection{Service Areas of SENAI Bahia/CIMATEC}

The vision is establishing SENAI Bahia/CIMATEC as the leading institution in the national vocational and technological education and to be recognized as an inducer of innovation and technology transfer to industry, working with the international standard of excellence.

The mission is to promote vocational and technological education, the innovation and transfer of industrial technologies, contributing to increase the competitiveness of the Brazilian industry and to help Bahia to attract new industry as well as to support Bahian companies in their internationalization strategies.

The overall objectives of SENAI Bahia/CIMATEC comprise 4 different dimensions which need to be taken into account to for being successful:

- Financial Sustainability: assure well-balanced revenue mix from different sources (compulsory, industry, public funding) and create synergies between different service areas

- Coverage of Regional Demand: fulfill short- to mid-term demand in focus industry sectors of Bahia and promote technology-based entrepreneurship

- National Industry Competitiveness: increase productivity and added value of Brazilian industry in production and technological development through the SENAI Bahia/CIMATEC Innovation Institutes (ISI) as part of the national ISI network

- Technological Leadership: drive future developments in focus competence areas and be recognized as national reference on global state-of-the-art level

Within this section the following questions regarding the Service Areas of SENAI Bahia/CIMATEC are answered:

- Which are the Main Service Areas of SENAI Bahia/CIMATEC and what are the Strategic Objectives of each Main Service Area?

- What is the current status of the Main Service Areas of SENAI Bahia/CIMATEC with regard to the related Strategic Objectives?

In the course of the project the four service areas were elaborated grouping similar products and services offered by SENAI Bahia/CIMATEC in one service area: technical education, higher education, technological services and R\&D\&I services.

For each of the four Service Areas strategic objectives were elaborated within the project. As a first step of the elaboration process challenges and objectives for each of the four Service Areas were identified and discussed on workshop. Building up on these strategic objectives for each Service Area were defined and refined according to further analysis results of the project. The final strategic objectives for each Service Area are described in the following.

\section{Technical Education}

Manage high growth and fulfill current and future demand of the Bahian industry by:

- Establishing technological culture (industry, students, teachers)

- $\quad$ Adapting the teaching model to new type of student (virtualization, state-of-the-art teaching methodologies)

- Increasing quality and efficiency of courses (standardization, modularization)

- Optimizing geographical distribution of education units in $\mathrm{Ba}-$ hia state

\section{Higher Education}

Attract and retain high potential students as well as qualified researchers/professors and expand higher education portfolio by:

- Building up clear differentiation features in comparison with other universities (industry-oriented innovation culture) and achieve the highest grade in the national rating;

- Adapting to international higher education standards (language, degrees);

- Increasing attractiveness of courses (flexible, dynamic programs, new teaching methods and technologies, international partnerships).

\section{Technological Services}

Offer competitive technological services and induce industry demand to increase market share by:

- Expanding service portfolio in a focused way (systematic planning for balancing all areas according to demand);

- Increasing efficiency of service delivery (costs, time) taking into account our financial sustainability;

- Optimize the value delivered to the customer and increasing reputation as trusted service provider (awareness, trust);

- Acting in a network environment and partnerships.

\section{R\&D\&I Services}

Establish R\&D / Innovation services in focus competence areas as a value added service for industry by:

- Building up competences (technological, creativity, business) and proving benefits of R\&D for industry;

- Focusing on applied research in cooperation with partners and networks (universities, institutes); 
- Enhancing the value added perceived by industry and reducing project costs using internal synergies with other service areas (share resources).

\subsubsection{Strategic Strengths \& Weaknesses Assessment}

After the definition of the four Service Areas of SENAI Bahia/ CIMATEC and the elaboration of respective strategic objectives, strengths and weaknesses of the Service areas were assessed with regard to the strategic objectives in the following three dimensions:

- Quantity: Capacities / Resources (infrastructure, competencies etc.)

- Quality: Quality of output/results, customer satisfaction

- Systematic: Management and systematic development of processes

The figure given below (Figure 6) summarizes the results of the assessment. On the $\mathrm{x}$-axis, the assessment results regarding quality are illustrated and on the y-axis, the assessment results regarding quantity. The diameter of the bubbles displays the assessment results regarding the dimension systematic.

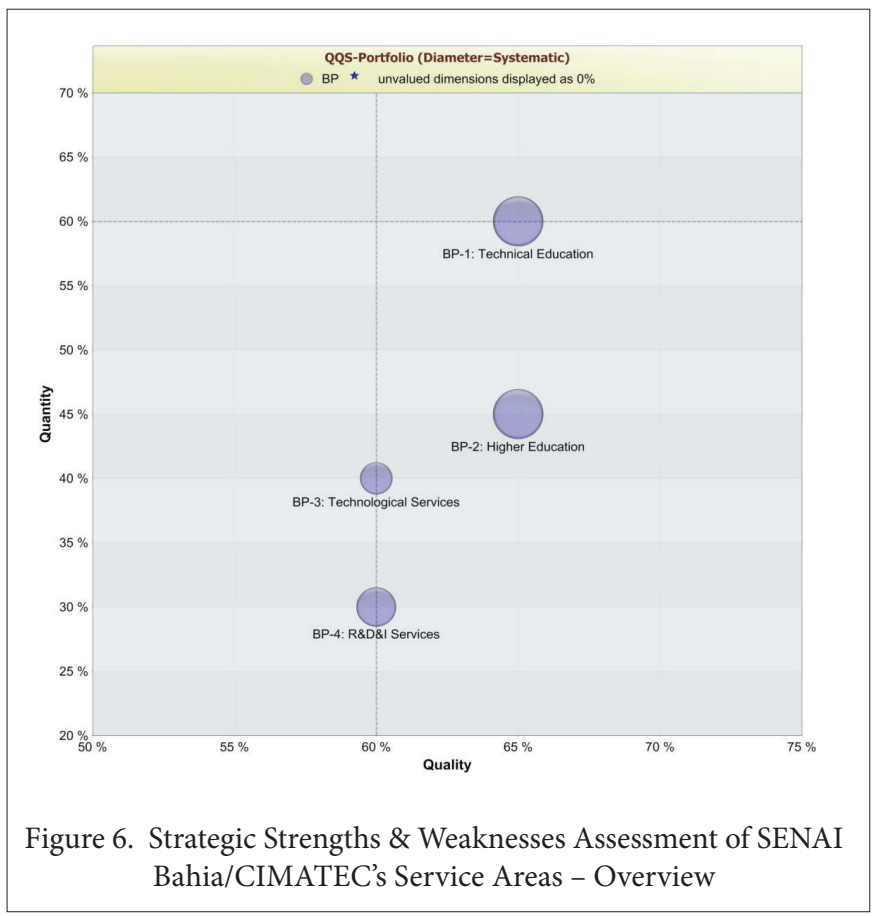

Regarding the dimension quality Technical Education and Higher Education are at the same level (65\%) followed by Technological Services and R\&D\&I Services (60\%). Thus, all of the four service areas are nearly at the same level with regard to the availability of capacities and resources leaving relatively small room for improvement in comparison to the other dimensions.
In contrast, the assessment results with regard to the quality of outputs show stronger disparities. With $60 \%$ Technical Education shows the highest assessment followed by Higher Education with $45 \%$ and Technological Services with 40\%. With $30 \%$ R\&D\&I Services has the lowest assessment of all Service Areas with regard to the quality of results showing the greatest potential for improvement. Taking into account all Service Areas the dimension quality shows higher potential for improvement than the dimension quantity.

In terms of the dimension systematic Technical Education and Higher Education are at the same level (50\%) followed by R\&D\&I Services with $35 \%$ and Technological Services with the lowest assessment result (25\%). Since the dimension systematic displays how well the development of the processes within the Service Areas is managed the results regarding the dimension systematic allow estimations on how the other two dimensions might develop in the future. Therefore, especially Technological Services with the lowest rating in this dimension should be taken care of. All in all, the dimension systematic leaves the biggest room for improvement taking into account the assessment results regarding all Service Areas.

\subsection{Focus Industry Sectors of SENAI Bahia/CIMATEC}

Within this section, the following questions regarding the Industry Sectors focused by SENAI Bahia/CIMATEC are answered:

- Which Global Megatrends and Technology Trends show high potential to be picked up by the Brazilian Industry?

- Which are the main trends in the national business environment with regard to SENAI Bahia/CIMATEC?

- Which are the Industry Sectors to be focused by SENAI Bahia/CIMATEC in the short-, mid- and long-term and what is their demand?

In order to answer the questions regarding the focus Industry Sectors given above a systematic approach was followed throughout the project (Figure 7). Building up on the global megatrends (described in 4.3.1), which were identified through extensive research trends, in the national business environment relevant to SENAI Bahia/CIMATEC were identified, discussed and assessed with regard to their impact on the four Service Areas of SENAI Bahia/CIMATEC (described in 4.3.2). In the following the long-term demand for services already offered at present or to be offered by SENAI Bahia/CIMATEC in the future were analyzed taking into account eight thoroughly researched global technology trends (described in 4.3.3) with relevance for SENAI Bahia/CIMATEC's focus Industry Sectors. Afterwards the mid-term demand of the national industry was focused (described in 4.3.4) followed by the analysis of the short-term demand of the regional industry (described in 4.3.5). 


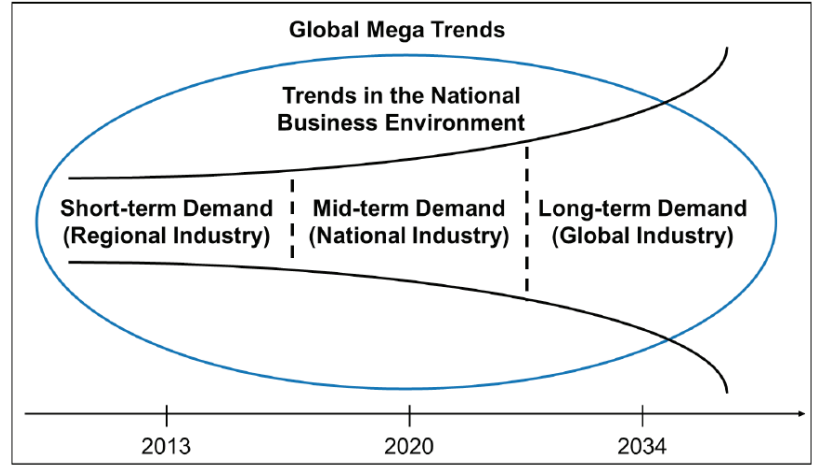

Figure 7. From Current to Future Demand in Light of Main Trends in the National Business Environment and Global Trends.

\subsubsection{Global Megatrends}

Global Megatrends are long-term processes of transformation with a broad scope and a dramatic impact that shape future markets. There are three characteristics in which megatrends differ from other trends:

- Time Horizon: Megatrends can be observed over decades. They can be projected at least 15 years into the future.

- $\quad$ Reach: Megatrends impact comprehensively on all regions and societal subsystems, whether in politics, society, or economy.

- Intensity of impact: Megatrends impact powerfully and extensively on all actors, whether it is governments, individuals and their consumption patterns, or corporations and their strategies.

In the following five current Global Megatrends with the characteristics illustrated above and relevant to the future development of SENAI Bahia/CIMATEC are described:

\section{Globalization}

- Partly because of energy dependences, power differences between industrialized and developing countries decrease;

- $\quad$ The BRIC states (Brazil, Russia, India \& China) are still the major players concerning global growth, but countries as Turkey, Mexico, Egypt, Iran and Vietnam have the potential to become serious rivals;

- In order to minimize costs, value chains are already split up geographically. Through the internet, services have become globally mobile as well;

- Political and economic problems such as the financial crisis and terrorism are solved globally;

- Trend to globalization: Global strategies with local adjustment.

\section{Demographic Development}

- Global population growth (up to 9 billion people in 2050) takes mainly place in developing countries;

- As a consequence and because of shortage in commodities such as water, migration from poorer to richer countries will rise;

- In contrast, the population in industrialized and some developing countries will age and decrease;

- Thereby, industrialized countries face financial deficits in their pensions and welfare system, while health-care costs and care-giving-expenses increase;

- Silver Markets: Main growth for consumer products and services in the field of health and leisure;

- Companies are challenged by brain drain and diversity management.

\section{Health}

- The level of medical care increases worldwide;

- The private health sector serves as a role model for public suppliers;

- $\quad$ Eldercare and an augmentation of chronic diseases such as adiposities, diabetes and allergies raise healthcare costs;

- In comparison with demographic change, the impact of technological progress on rising expenses is much higher;

- The trend is toward more individual responsibility for one's own medical condition;

- The increase of health awareness has led to the convergence of markets and many new products, especially in the areas of nutrition, pharmaceuticals, and cosmetics.

\section{Environment}

Environmental technologies can become key drivers for economies: Sustainable water management, mobility, green power generation and efficient technologies have potential for growth;

- $\quad$ Scarce resources and increasing commodity prices lead to techniques that enhance energy and resource productivity, development of optimized materials and new technologies and efficient production;

- Companies face greater environmental responsibility (CO2-emission is to be treated similar to a commodity);

- Solar power is the most important energy source on the globe (Europe is advised to concentrate on power production based on wind and water and a decentralized energy supply system); 
- Electric vehicles still face some obstacles concerning price, usability, operating distance caused by insufficient battery capacity and lack of infrastructure;

- A strong competition between countries and regions for the cutting edge in green technologies is assumed.

\section{Technological development}

The convergence of technologies and research fields will become more important, e.g. the „NBIC“-discipline (nano and biotechnology, information technology \& cognitive sciences): Miniaturizing of technologies / nanotechnology; Ambient Intelligence; Robotics; Biotechnology and genetic engineering; Bionics; Cloud Computing; Individualization leads to mass customization; Green technologies.

\subsubsection{Trends in the National Business Environment}

Building up on the Global Megatrends in a next step the national business environment was analyzed with regard to threats and opportunities for SENAI Bahia/CIMATEC. Throughout the analysis, the following dimensions were taken into account following the scheme of the PEST-Analysis: Political Trends; Economic Trends; Social Trends; and Technological Trends.

The results from the workshop are illustrated for the dimension Social Trends in Table 1. The different trends for each dimension were listed and their impact with regard to the four service areas of SEBAI Bahia is illustrated whereas a positive impact is represented by a "+" and a negative impact by a "-_. The more "+” and "-“ are shown, the higher is the impact of the trend on the respective service area.

\begin{tabular}{|c|c|c|c|c|}
\hline Social Trends & $\begin{array}{l}\text { Technical } \\
\text { Education }\end{array}$ & $\begin{array}{c}\text { Higher } \\
\text { Education }\end{array}$ & $\begin{array}{l}\text { Technological } \\
\text { Services }\end{array}$ & $\begin{array}{l}\text { R\&D\&1 } \\
\text { Services }\end{array}$ \\
\hline $\begin{array}{l}\text { Technical education and jobs perceived as for lower class, but in the } \\
\text { future perception will change due to middle class (5-10 years) }\end{array}$ & 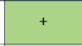 & indirect effect & & \\
\hline Demography: higher life expectation & & & & + \\
\hline $\begin{array}{l}\text { Women increasingly in technical jobs("women in science" and maybe } \\
\text { another project "women entrepreneurs") }\end{array}$ & + & + & & \\
\hline $\begin{array}{l}\text { Higher penetration of domestic computers (opportunity for new teaching } \\
\text { models) }\end{array}$ & + & + & & \\
\hline Urbanization (migration towards cities) & + & & & \\
\hline Green economy is developing due to unique biodiversity of Brazil & & & + & + \\
\hline
\end{tabular}

Table 1. Social Trends in the National Business Environment Relevant To SENAI Bahia/CIMATEC.

\subsubsection{Long-term Demand - Global Industry}

To estimate the future demand of industries targeted by SENAI Bahia/CIMATEC eight global technology trends were presented and discussed. The eight global technology trends presented within the workshops of the project were identified through extensive research and a systematic analysis of numerous sources: Accenture (2013), Balmer (2010), Capgemini (2011), Deloitte (2013), Goh (2013), IBM (2013), Klingner (2012), Manyika et al. (2013), Matuszak (2013) and Millett (2012). They represent technologies that are already or will be substituting old technologies which have reached or will reach their physical limit. They are: Renewable Energy, Energy Storage, Mobile Internet, Cloud Computing, Internet of Things, Advanced Robotics,
NanoTechnology, 3D Printing. Each of the technology trends given above is described in the following paragraphs.

\section{Renewable Energies}

Renewable energy is energy gained from natural resources such as sunlight, wind, rain, tides, waves and geothermal heat. Energy can be generated through different technologies: Wind power; Hydropower; Photovoltaic \& Solar Thermal; Biofuel and Bio Mass; Geothermal Energy. Potential applications of renewable energy are: electricity generation; water desalination systems; water heating; air conditioning systems.

\section{Advanced Energy Storage}

Energy storage systems convert electricity into a form that can be stored and converted back into electrical energy, which can be stored through different technologies: Pumped hydro-electric storage; Compressed Air Energy Storage; Batteries (Li-ion, lead acid etc.); Fly Wheel Energy Storage; Superconducting Magnetic Energy Storage; Super Capacitors; Fuel Cells. Potential applications of advanced energy storage are: Power Grids \& Distributed Energy; Electric Drive Transportation; Mobile Devices.

\section{Mobile Internet}

The mobile Internet is a combination of mobile computing devices, high-speed wireless connectivity, and applications. Future developments will lead to: Increased processing power and connectivity; Smaller and new devices (e.g. google glasses); More intuitive usage (e.g. gesture recognition); Integration of further types of sensors. Examples of potential applications of the mobile internet are: Location Based Services (especially); Information; Banking; Education; Health.

\section{Cloud Computing}

Cloud computing is a model for enabling on-demand network access to a shared pool of configurable computing resources that can be rapidly provisioned and released with minimal management effort or service provider interaction. Features of cloud services are: On-demand Self Service; Broad Network Access; Resource Pooling; Rapid Elasticity; Measured Services. The applications of cloud computing are: Infrastructure as a Service (IaaS); Platforms as a Service (PaaS); Software as a Service (SaaS).

\section{The Internet of Things}

The Internet of things (IoT) can be broadly defined as a global network infrastructure integrating the physical world with the virtual world of the internet by linking uniquely identified physical and virtual objects, things and devices through: the exploitation of data capture (sensing), communication and actuation capabilities. Potential applications for the internet of things are: Tracking Behavior; Enhanced Situational Awareness; Sensor-driven Decision Analytics; Process Optimization; Optimized Resource Consumption; Complex Autonomous Systems. 


\section{Advanced Robotics}

Devices that act largely, or partly, autonomously, that interact physically with people or their environment and that are capable of modifying their behavior based upon sensor data. The technology subsets of advanced robots are Sub-systems, components and supporting technologies. In the subsystems, the unique attributes of an advanced robot are most visible: Mobility; Manipulation; Control; Cognition; Real world interfaces. The application of advanced robots is very broad and ranges from industry robots to leisure robots.

\section{Nano Technology}

Nanotechnology is the application of scientific knowledge to manipulate and control matter at the nano scale level to make use of size and structure dependent properties and phenomena distinct from those associated with individual atoms or molecules or with bulk materials. Within the commercialization of nanotechnology, there exist three broad categories: Nanostructured materials; Nanotools; Nanodevices3D Printing. Due to its nature nanotechnology can be applied in many ways - examples are: Diagnostic tools and treatments for cancer; Water purification; Fast charging batteries with high power density.

\section{D Printing}

3D Printing or Additive Manufacturing is a process of making a 3-dimensional solid object of virtually any shape laying down successively layer-by-layer of a material in different shapes. Applied technologies are: Fused Deposition Modeling; Electron Beam Freeform Fabrication; Direct Metal and Selective Laser Sintering; Electron Beam Melting \& Selective Laser Melting; Selective Heat Sintering; Plaster; Laminated Object Manufacturing; Stereolithographic; Digital Light Processing. Industrial applications comprise rapid prototyping, rapid manufacturing, mass customization \& mass production. In addition $3 \mathrm{D}$ printing can be used domestically as well as for $\mathrm{R} \& \mathrm{D}$ and is offered as a service by companies.

\subsubsection{Mid-To Long-Term Demand - National Industry}

In the workshops regarding the national mid- to long-term demand 14 different Industry Sectors were identified that are focused by SENAI BA. The identified Industry Sectors are: Energy; Automotive \& Metal Mechanics; Chemical \& Petrochemical; IT, Communication \& Electronics; Construction \& Infrastructure; Agribusiness and Food \& Beverage; Mining; Health; Naval \& Offshore; Defense \& Aeronautics; Education Providers; Pharmaceutical \& Cosmetics; Utilities \& Water; Metallurgy.

For each of the focus Industry Sectors of SENAI Bahia/CIMATEC at national level the specific demand was described and matched with global megatrends and technology trends. In the following table (Table 2) the specific demand of each Industry Sector is described and demands corresponding with the global megatrends and technology trends are highlighted with bold letters.

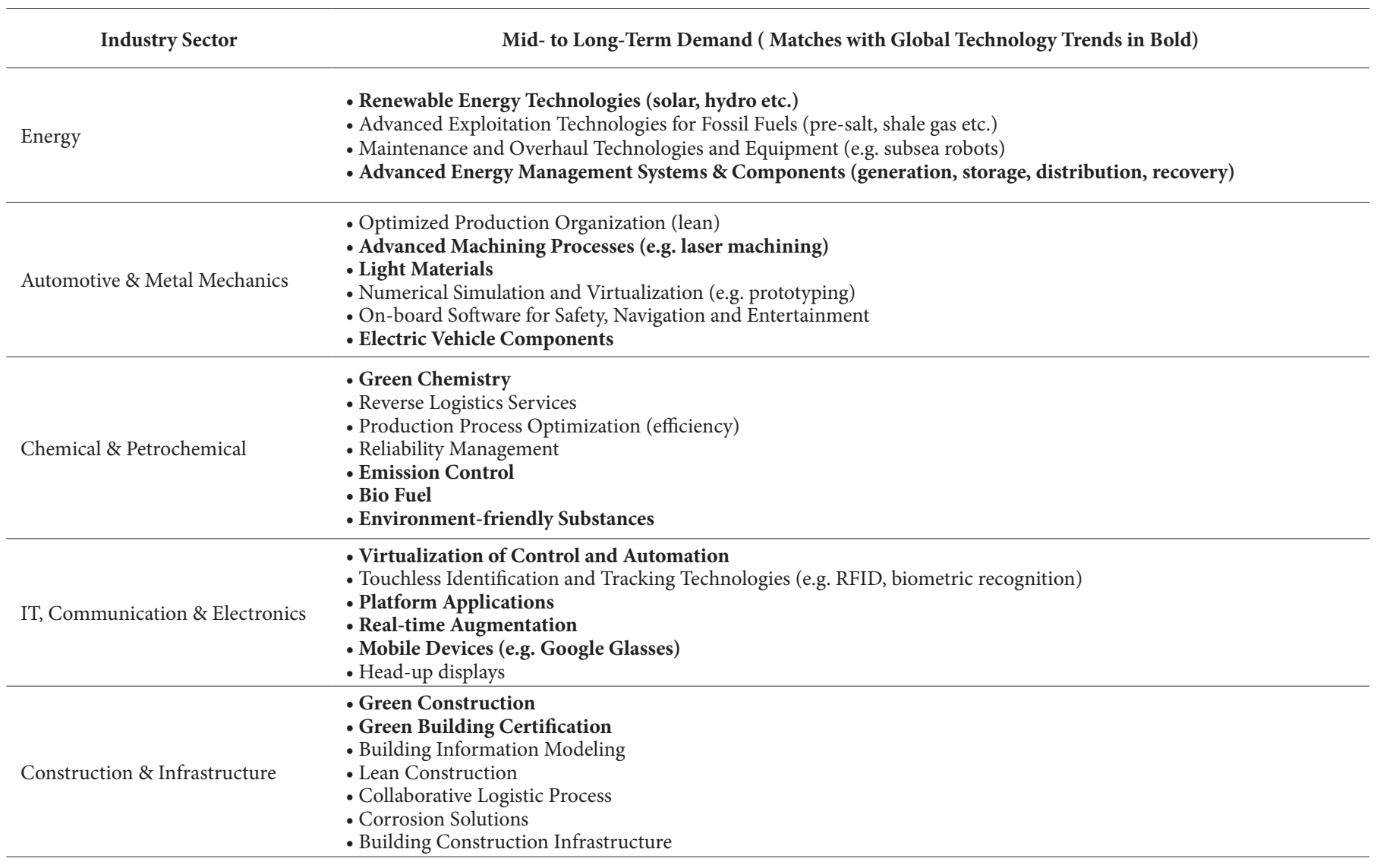

ISSN: 0718-2724. (http://jotmi.org) 
Industry Sector

Mid- to Long-Term Demand ( Matches with Global Technology Trends in Bold)

\begin{tabular}{|c|c|}
\hline $\begin{array}{l}\text { Agribusiness and Food \& } \\
\text { Beverage }\end{array}$ & $\begin{array}{l}\text { - Smart Farming } \\
\text { - Sensors and Automation for High Precision Agriculture } \\
\text { - Small Energy Generators for Remote Equipment } \\
\text { - Smart and Active Packaging (functional) } \\
\text { - Methods for Food Safety } \\
\text { - Preserved Food Products } \\
\text { - New Materials for the Food Industry }\end{array}$ \\
\hline Mining & $\begin{array}{l}\text { - Geological Surveys } \\
\text { - Safety in Mining } \\
\text { - Recovery of Low Content Ores (residues) } \\
\text { - Energy Harvesting } \\
\text { - Technological Processes for Exploitation of Rare Geological Materials } \\
\text { - Processes for Utilization of Mining Residues }\end{array}$ \\
\hline Health & $\begin{array}{l}\text { - New Image Diagnostics } \\
\text { - Robots for Surgery } \\
\text { - Health Control Gadgets \& Wireless Health } \\
\text { - Sensors for Healthcare } \\
\text { - Big Data \& Data Interoperability } \\
\text { - New Materials for Implants and 3D Printing (e.g. organs) } \\
\text { - Intelligent Taylor-made Implants/ / Prostheses } \\
\text { - Advanced Drug Delivery }\end{array}$ \\
\hline Naval \& Offshore & $\begin{array}{l}\text { - Advanced Joining Processes (hybrid) } \\
\text { - Metal Forming Simulation } \\
\text { - Refurbishment of Old Platforms } \\
\text { - Autonomous Platforms }\end{array}$ \\
\hline Defense \& Aeronautics & $\begin{array}{l}\text { - Advanced Joining Processes (hybrid) } \\
\text { - Light Materials } \\
\text { - Embedded Systems / System Integration } \\
\text { - Armoring and Concealing Materials } \\
\text { - Autonomous Robot Soldiers } \\
\text { - Surveillance Equipment } \\
\text { - Big Data Analysis }\end{array}$ \\
\hline Education Providers & $\begin{array}{l}\text { - Distance Learning Techniques } \\
\text { - Business Models for Distance Learning } \\
\text { - Educational Games } \\
\text { - Data Interoperability and Mobile Content } \\
\text { - Bring Your Own Device } \\
\text { - Concurrent Engineering } \\
\text { - Simulation Techniques }\end{array}$ \\
\hline Metallurgy & $\begin{array}{l}\text { - New Materials (special alloys) } \\
\text { - High Precision Laser Processing \& Materials } \\
\text { - Recycling Technologies (e.g. for cars) \& Solid Waste and Alloy Recovery Treatment } \\
\text { - Waste Prevention } \\
\text { - Advanced Technologies for Morphology Studies } \\
\text { - Simulation, Modeling \& Testing } \\
\text { - Automation \& Robotization }\end{array}$ \\
\hline
\end{tabular}

Table 2. Demand of the Brazilian Industry Mid- to Long-term - Specific Demand of Industry Sectors. 


\subsubsection{Short- to Mid-term Demand - Regional Industry}

In the workshops regarding the regional demand seven Industry Sectors were identified that are focused by SENAI Bahia/CIMATEC in the short- to mid-term at regional level. The identified Industry Sectors are: Energy; Automotive \& Metal Mechanics; Chemical \& Petrochemical; IT, Communication \& Electronics; Construction \& Infrastructure; Agribusiness and Food \& Beverage; Mining.

Five of the seven Industry Sectors given above were assessed throughout the workshops according to the specific demand in the four Service Areas of SENAI Bahia/CIMATEC showing specifically high dynamic demand in the short- to mid-term (Figure 8).

\begin{tabular}{|c|c|c|c|c|c|}
\hline \multirow[b]{2}{*}{ INDUSTRY SECTORS } & \multicolumn{5}{|c|}{ SENAI BA SERVICE AREAS } \\
\hline & $\begin{array}{l}\text { Technical } \\
\text { Education }\end{array}$ & $\begin{array}{l}\text { Higher } \\
\text { Education }\end{array}$ & $\begin{array}{l}\text { Technological } \\
\text { Services }\end{array}$ & R\&D\& Services & $\Sigma$ \\
\hline $\begin{array}{l}\text { Energy (Oil \& Gas, Renewable } \\
\text { Energies) }\end{array}$ & 3 & 2 & 3 & 3 & 11 \\
\hline $\begin{array}{l}\text { Automotive \& Metal } \\
\text { Mechanics }\end{array}$ & 2 & 2 & 3 & 2 & 9 \\
\hline Chemical \& Petrochemical & 2 & 1 & 2 & 2 & 7 \\
\hline $\begin{array}{l}\text { IT, Communication \& } \\
\text { Electronics }\end{array}$ & 2 & 2 & 1 & 2 & 7 \\
\hline Gonstruction & 3 & 2 & 2 & 1 & 8 \\
\hline$\Sigma$ & $12)$ & 9 & 11) & 10 & \\
\hline \begin{tabular}{|l|c|}
\multicolumn{2}{|c|}{ Legend for Assessment } \\
0 & no demand \\
1 & littledemand \\
2 & medium demand \\
3 & high demand \\
\end{tabular} & & & & & \\
\hline
\end{tabular}

Figure 8. Assessment of the Regional Industry Demand in Bahia in the Short- to Mid-Term Perspective

\subsection{Competence Areas of SENAI Bahia/CIMATEC}

Within the project future Competence Areas for SENAI Bahia/CIMATEC were elaborated long-term demand-oriented taking into account the competencies already existent at SENAI Bahia/CIMATEC in the present and the analysis results regarding SENAI Bahia/CIMATEC's focus Industry Sectors. For the elaboration of the future Competence Areas of SENAI Bahia/CIMATEC the generic approach illustrated below was used (Figure 9).

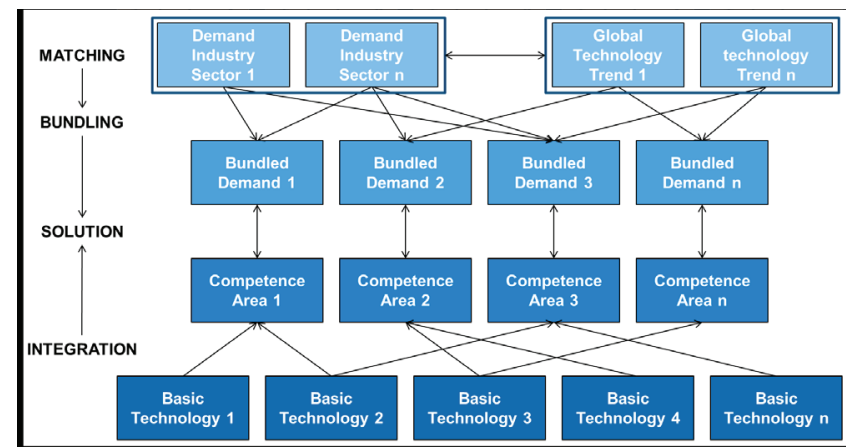

Figure 9. Generic Approach for the Elaboration of Future Competence Areas
Following this approach similar short- to mid-term demands of different focus Industry Sectors of SENAI Bahia/CIMATEC are matched with global technology trends relevant to the respective demands first and then bundled to long-term industry demands (Figure 10).

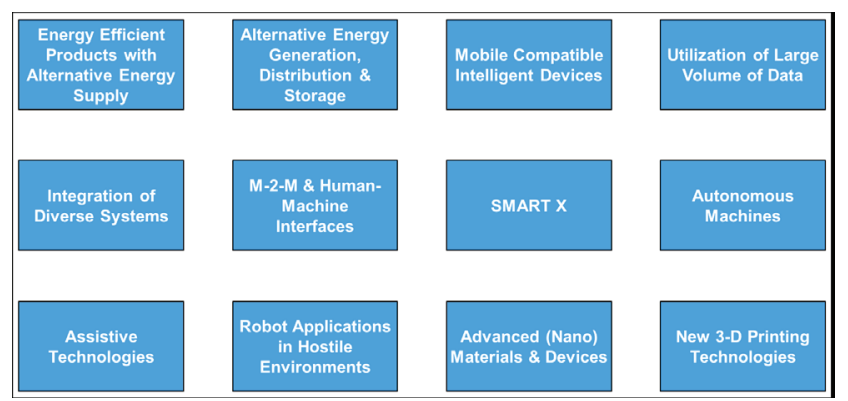

Figure 10: Bundled Industry Demand as the Match of Short-to Mid-Term Industry Demand and Technology Trends

In order to cover these bundled demands and deliver solutions to the respective Industry Sectors different basic technologies (Figure 11) have to be integrated into competence areas where services/solutions are provided to the industry.

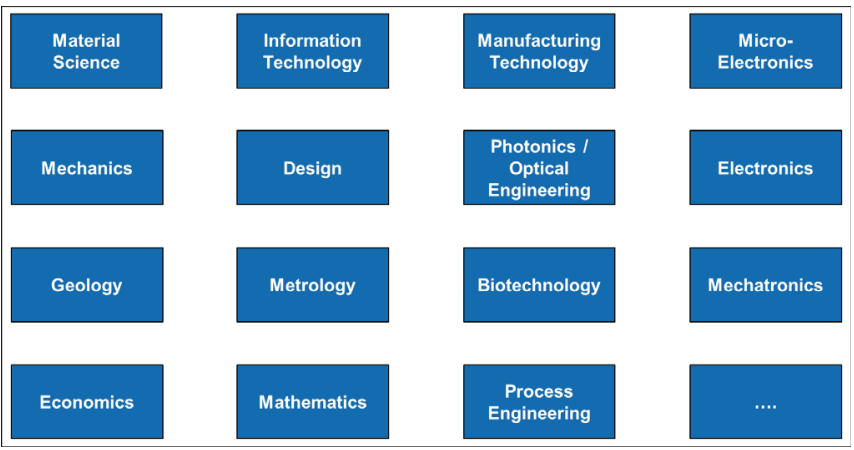

Figure 11. Basic Technologies as the Basic Components of ApplicationOriented Competence Areas

In the figure given below (Figure 12) the exemplary elaboration process of the future Competence Area "Big Data Analysis \& Processing" is illustrated. 


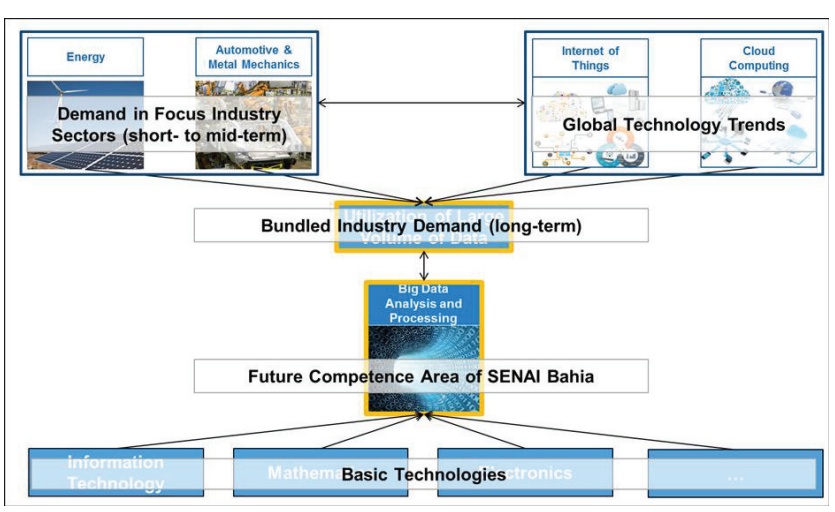

Figure 12. Exemplary Elaboration Process of Future Competence Areas
In this example the short- to mid-term demands of the Industry Sectors "Energy" and "Automotive \& Metal Mechanics" are matched with the global technology trends "Internet of Things" and "Cloud Computing" and are bundled to the long-term industry demand "Utilization of Large Volume of Data". In order to cover this demand among various other basic technologies "Information Technology", "Mathematics" and "Electronics" are integrated into the future Competence Area "Big Data Analysis \& Processing" to enable SENAI BA to provide appropriate solutions to the respective Industry Sectors and cover the bundled long-term demand.

By applying the approach described generically and exemplary above 10 future Competence Areas of SENAI Bahia/CIMATEC were elaborated within the project. These future Competence Areas are described in the following table (Table 3 ).

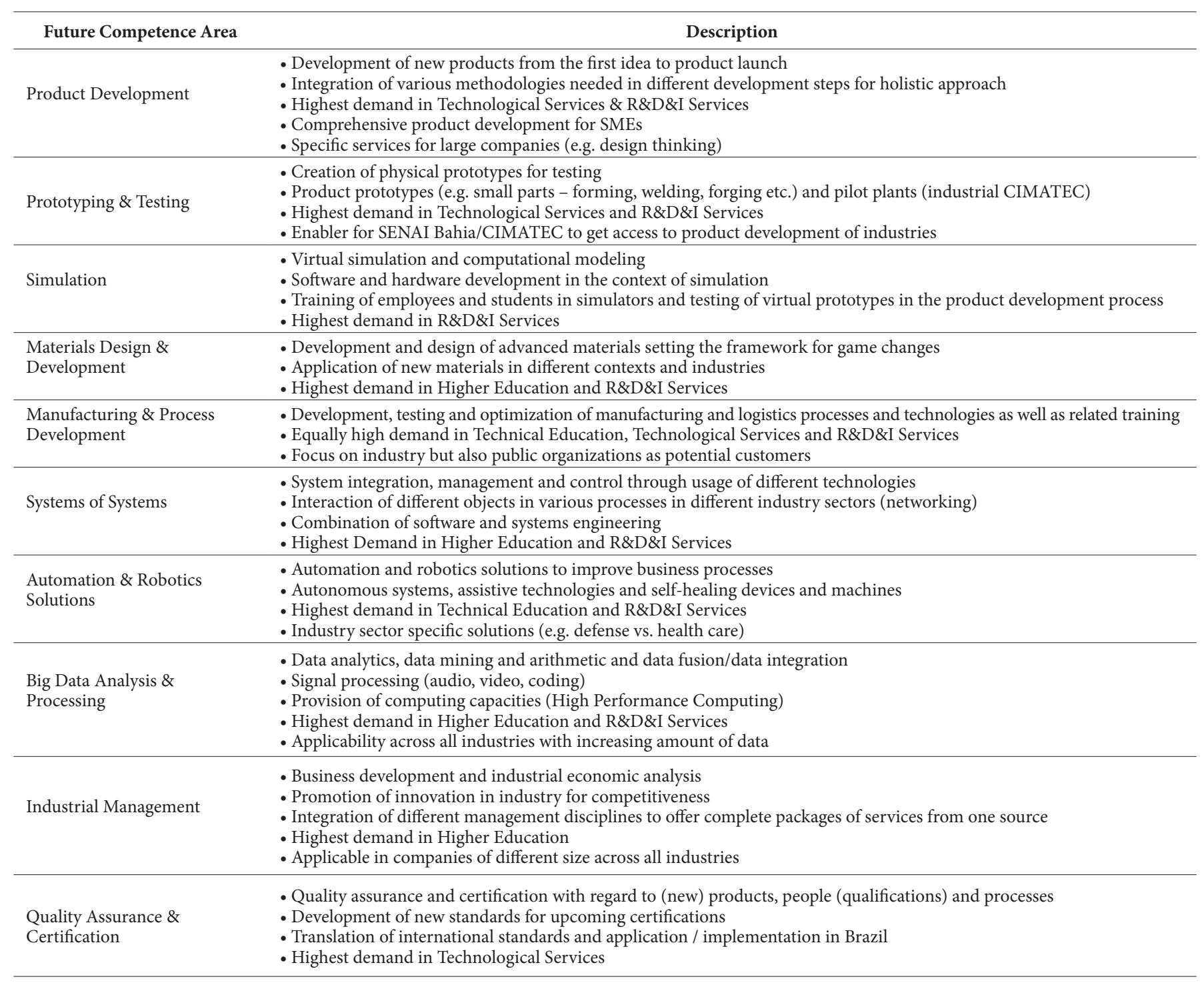

Table 3. Description of SENAI Bahia/CIMATEC's Future Competence Areas 
After the elaboration of the 10 future competence areas described above each future Competence Area was assessed with regard to two dimensions using the related guiding questions:

\section{Future Demand:}

- How high is the demand in the mid- to long-term in the Brazilian Industry?

- In which Service Areas will the industry have the highest demand regarding the Competence Area?

\section{Competence Readiness:}

- How much of the needed knowledge / equipment / personnel already exist?

- How well are the relevant basic Technologies already developed?

The results of the assessment are illustrated in the Competence Area Portfolio given below (Figure 13). Within the portfolio, the different future Competence Areas of SENAI Bahia/CIMATEC are arranged according to the respective assessment of the competence readiness displayed on the $\mathrm{x}$-axis and according to the respective assessment of the future industry demand displayed on the y-axis.

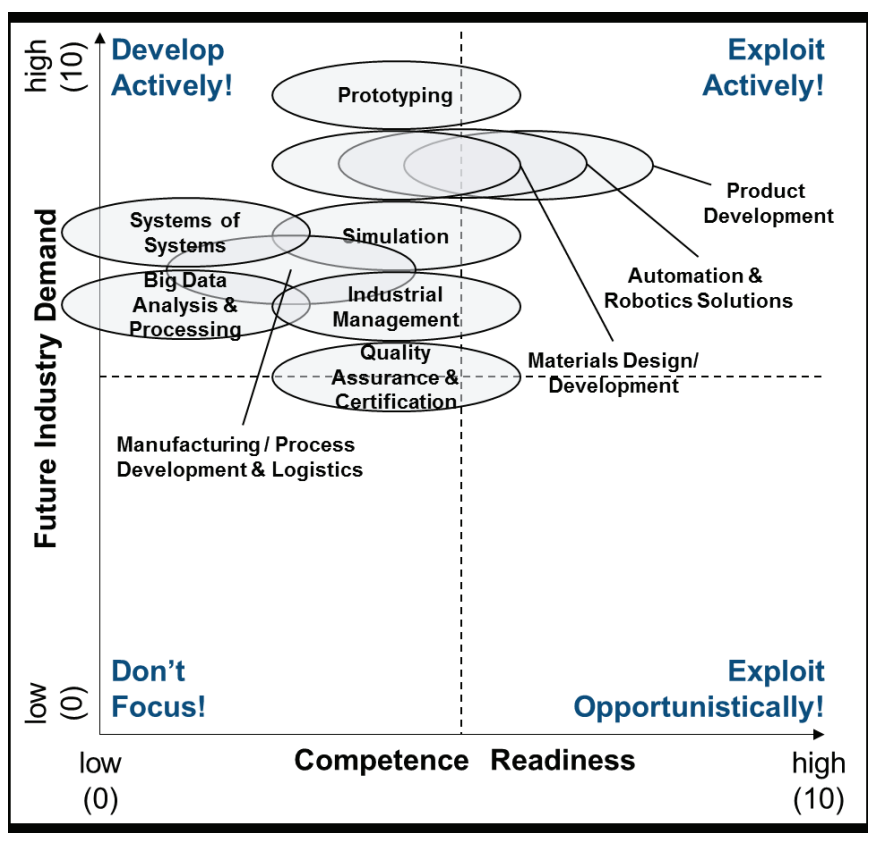

Figure 13. Competence Area Attractiveness Portfolio

The portfolio is sub-divided into four quadrants, which offer standard recommendations for action with regard to the development of the future Competence Areas:
- Exploit Opportunistically: The competence readiness of a Competence Area in this quadrant is relatively high, but the future demand for the Competence Area is relatively low. Therefore, chances should be taken, if they appear, but no further effort should be put into further development here.

- Exploit Actively: The competence readiness of a Competence Area in this quadrant is relatively high and the future demand for the Competence Area is relatively high as well. Therefore, the upcoming industry demand can be exploited actively without putting effort into the development of the Competence Area in the short-term. In the long-term further development might become necessary though to be able to continuously profit from the future high demand.

- Develop Actively: The competence readiness of a Competence Area in this quadrant is relatively low, but the future demand for the Competence Area is relatively high. Therefore, the Competence Area needs to be actively developed in order to be able to profit from the high demand in the future.

- Do not Focus: The competence readiness of a Competence Area in this quadrant is relatively low and the future demand for the Competence Area is relatively low as well. Since there will be no demand for this fairly developed Competence Area in the future no efforts should be put in further development.

Since nearly all of the future Competence Areas of SENAI Bahia/ CIMATEC are located in the third quadrant "Develop Actively" the Competence Areas have to be looked at in more detail to decide how the single future Competence Areas should be developed.

In the Figure 14 the assessment boundaries were shifted to gain a deeper understanding on the differences between the Competence Areas and to make a prioritization possible.

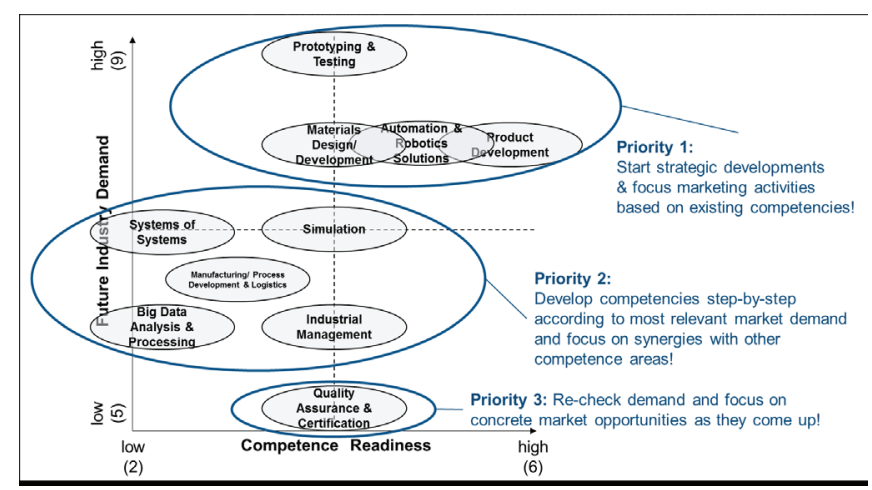

Figure 14. Prioritization of Competence Areas (Zoomed Attractiveness Portfolio) 
As illustrated in the figure, the future Competence Areas are prioritized according to the effort / steps that should be taken to further develop the future Competence Areas for decision support:

Priority 1 - Start strategic developments \& focus marketing activities based on existing competencies: Prototyping \& Testing; Product Development; Automation \& Robotics Solutions; Materials Design / Development.

Priority 2 - Develop competencies step-by-step according to most relevant market demand and focus on synergies with other competence areas:
Simulation; Systems of Systems; Manufacturing / Process Development \& Logistics; Industrial Management; Big Data Analysis \& Processing

Priority 3 - Re-check demand and focus on concrete opportunities as they come up: Quality Assurance \& Certification

In the following table, (Table 4) the future Competence Areas are ranked according to their respective assessment of the future industry demand and the competence readiness. Furthermore it is illustrated how big the future industry demand in the Service Areas of SENAI Bahia/CIMATEC is - from little "+" to large “+++" demand.

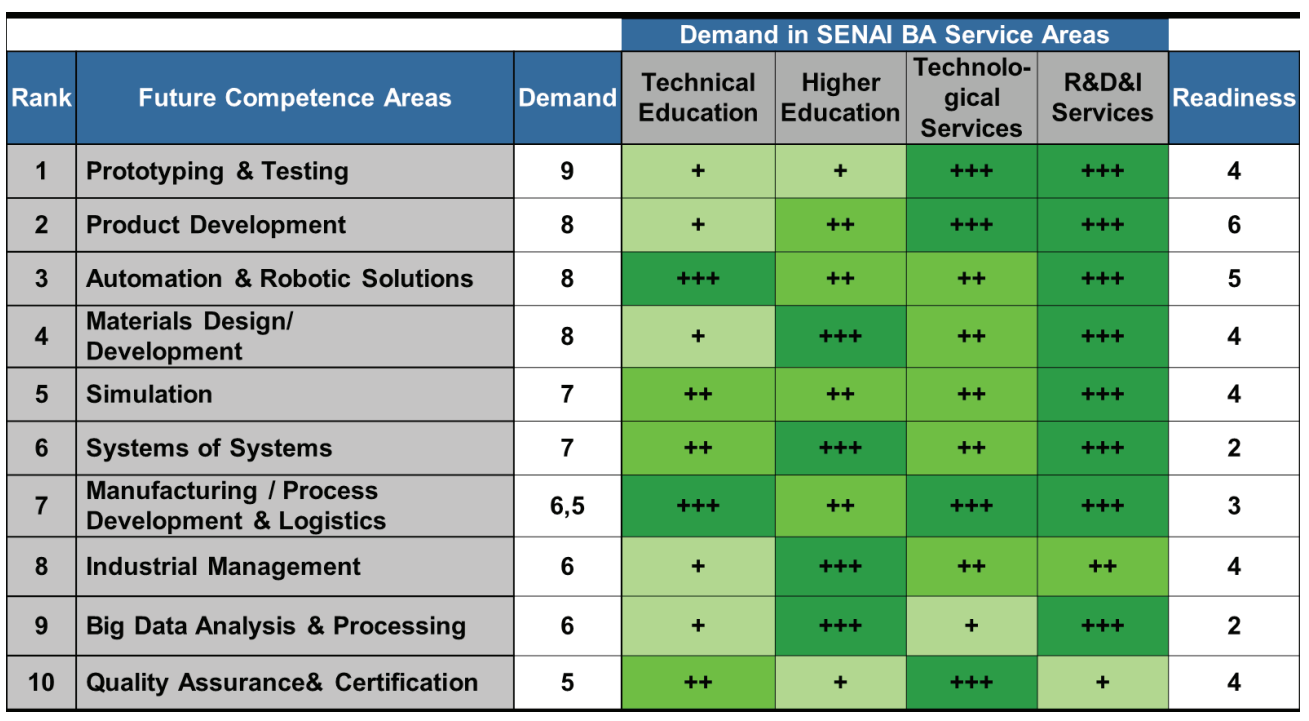

Figure 4. Ranking of Future Competence Areas

\section{Discussion}

The overall results of the study can be summarized as follows:

- Integrated Strategy Framework separates three distinct perspectives for strategic development of SENAI Bahia/CIMATEC in the long-term;

- Analysis of Global Mega-Trends and National Framework Conditions;

- Analysis of Regional and National Demand in Focus Industry Sectors (Short- to Mid-Term);

- Investigation of Global Technology Trends to Match and Bundle Future National Industry Demand (Long-Term);

- Demand-Oriented Definition and Prioritization of SENAI Bahia/CIMATEC's Future Competence Areas;

- Assessment of Readiness in Future Competence Areas according to Relevant Basic Technologies.
- The results and benefits generated with regard to SENAI Bahia/ CIMATEC's Service Areas can be summarized as follows:

- Prospection of revenue development per Service Area until 2034 shapes the future development of SENAI Bahia/CIMATEC in quantitative terms and allows strategic planning of budgets, headcounts and scope of facilities;

- $\quad$ Strategic objectives for each Service Area provide guidance for operationalization of strategy and for strategic management and monitoring systems;

- Assessment of strengths and weaknesses in each Service Area shows improvement potential for achieving strategic growth and realizing necessary gains in productivity to balance costs and quality according to long-term requirements;

- Mapping of Service Areas with short-/mid-term regional demand per Focus Industry Sector and long-term demand per Future Competence Area allows step-by-step development of each Service Area in a market- and topic-focused way. 
The results and benefits generated with regard to SENAI Bahia/CIMATEC's focus Industry Sectors can be summarized as follows:

- Global megatrends and national framework conditions set the "real world" frame for SENAI Bahia/CIMATEC's strategic development according to political, social, economic and technological trends;

- Division of regional short-term and national mid-term demand and prioritization of industry sectors allow a clear focus and enable a step-by-step development of SENAI Bahia/CIMATEC's service portfolio for Bahian and Brazilian industry;

- Investigation of sector-specific industry demand allows well-targeted customization and marketing of SENAI Bahia/CIMATEC's services for specific target groups;

- Prospection of transversal long-term industry demand based on global technology trends and mid-term demand of focus industry sectors build basis for demand-oriented development of Future Competence Areas.

The results and benefits generated with regard to SENAI Bahia/CIMATEC's Competence Areas can be summarized as follows:

- Demand- and trend-based definition of Competence Areas ensures market-oriented development of technological leadership in the next 20 years;

- Interdisciplinary and solution-oriented character of Competence Areas sets focus on future industry applications;

- Assessment of future industry demand and today's readiness leads to clear prioritization of Competence Areas for SENAI Bahia/CIMATEC's overall strategic development backed up by qualitative reasoning;

- Deriving Basic Technologies from Future Competence Areas allows operationalization of long-term and demand-oriented competence development in top-down/ bottom-up approach;

- Analysis of industry demand per Service Area allows generating synergies in each Competence Area across all Service Areas.

This work made possible to map key skills to be developed by Center of R\&D\&I to meet the demands of medium to long-term manufacturing industry, contributing to the increase of competitiveness of Brazilian industry. The definition of competency areas based on demand and trends provides the interdisciplinary oriented development to the market and technological leadership in the next twenty years. In order to achieve SENAI Bahia/CIMATEC's overall objectives a continuous organizational transformation has to be initiated with regard to the three dimensions of the Integrated Strategy Framework using the results generated within the project. For this purpose, three distinct large-scale strategic programs have to be developed for SENAI Bahia/ CIMATEC's Service Areas, focus Industry Sectors and Competence Areas taking into account available and further needed resources.

\section{References}

Accenture. (2013). Accenture Technology Vision 2013: Every Business is a Digital Business. Retrieved 20 October 2014, from https://www.accenture.com/us-en/ /media/Accenture/Conversion-Assets/DotCom/Documents/Global/PDF/Technology_1/Accenture-Technology-Vision-2013.pdf

Balmer, B. (2010). Global Mega Trends to 2020 and their Impact on Chemicals and Materials Companies. New York: Frost \& Sullivan.

Capgemini. (2011). TechnoVision \& sustainability: How TechnoVision will help you, to become sustainable. Retrieved 20 October 2014, from http://www.capgemini.com/resources/technovision-sustainability

Deloitte. (2013). Tech Trends 2013: Elements of postdigital. Retrieved 21 October 2014, from http://www2.deloitte.com/au/en/pages/technology/articles/tech-trends-2013.html

Freitas Filho, A., Paez, M., \& Goedert, W. (2002). Strategic planning in public $\mathrm{R} \& \mathrm{D}$ organizations for agribusiness. Technological Forecasting and Social Change, 69(8), 833-847. http://dx.doi.org/10.1016/ s0040-1625(01)00139-1

Goh, R. (2013). Global Technology Trend Report (1st ed.). Morgan McKinley. Retrieved from http://www.morganmckinley.ie/sites/morganmckinley.ie/files/GlobalTechnologyReport.pdf

IBM. (2013). Global Technology Outlook 2013 (1st ed.). New York: International Business Machines (IBM). Retrieved from http://www.zurich. ibm.com/pdf/isl/infoportal/Global_Technology_Outlook_2013.pdf

Klingner, R. (2012). The Fraunhofer Model in Germany - closing the gap between science and industry. Science and Technology Policy Institute. Retrieved 21 October 2014, from http://www.stepi.re.kr/ module/seminaDownFile.jsp? cmsCd=CM0038\&ntNo=26796\&sb$\mathrm{No}=4 \&$ fileFlag $=\mathrm{spk}$

Manyika, J., Chui, M., Bughin, J., Dobbs, R., Bisson, P., \& Marrs, A. (2013). Disruptive technologies: Advances that will transform life, business, and the global economy. McKinsey.com. Retrieved 18 October 2014, from http://www.mckinsey.com/insights/business_technology/ disruptive_technologies

Matuszak, G. (2013). 2013 Technology Industry Business Outlook Survey (1st ed.). USA: KPMG. Retrieved from https://www.kpmg.com/ US/en/IssuesAndInsights/ArticlesPublications/Documents/technology-outlook-survey-2013.pdf

Millett, S. (2012). Technology Trends \& Future: Predictions 2013 (1st ed.). Computer Sciences Corporation (CSC). Retrieved from http:// assets1.csc.com/au/downloads/Technology_trends_and_future_predictions_2013_CSC_Australia.pdf

Suzila, I., Alinda, A., Suhadak, I., \& Zurinah, S. (2013). ICT Innovation Strategy in Malaysia Public Research Institutes and Government Agencies. International Journal of Computer Communications and 
Networks (IJCCN), 3(3), 1-12. Retrieved from http://iartc.net/index. php/Networks/article/view/65/54

Weigand, K., Flanagan, T., Dye, K., \& Jones, P. (2014). Collaborative foresight: complementing long-horizon strategic planning. Tech- nological Forecasting and Social Change, 85, 134-152. http://dx.doi. org/10.1016/j.techfore.2013.08.016

Zouain, D. (2001). Gestão de instituições de pesquisa. Rio de Janeiro, Brasil: FGV Editora. 